\title{
MORPHOLOGIC AND BIOCHEMICAL STUDIES \\ ON THE EXPERIMENTAL CHRONIC ISCHEMIC MYOCARDIUM WITH THE AMEROID CONSTRICTOR*
}

\author{
TAKashi Katagiri, Kenji Toba, Youichi Takeyama, \\ KoH OzaWA, AND HirokazU NitTani
}

1. Morphologic as well as biochemical alterations in chronic ischemic myocardial tissue without infarction were studied in dogs utilizing the Ameroid constrictor.

2. Serum creatine kinase** activity elevated at around three weeks after placing the Ameroid constrictor around the circumflex branch of the left coronary artery suggestive of myocardial tissue injury followed by the initial activation caused by surgery.

3. Subendocardial proliferation of connective tissue was observed in about $60 \%$ of the experiments, but the middle and the subepicardial muscles were morphologically intact.

4. The marked increase in glycogen particles was observed in the subendocardial muscle cells in most of the experiments, and mild features of myocardial cellular necrosis were found in approximately $60 \%$ of the experiments.

5. ATPase activities of the structural proteins as well as sarcoplasmic reticulum in the ischemic myocardium showed relatively higher values than those in the non-ischemic myocardium. However, no substructural changes were observed in SDS gel electrophoresis in both the fractions.

6. The alterations in the chronic myocardial ischemia are supposed to be essentially the same as those in myocardial necrosis followed by acute coronary occlusion.

$\mathbf{C}^{4}$ HRONIC ischemic heart diseases, such as coronary sclerosis, coronary insufficiency, angina pectoris, etc., which are ordinarily the

\section{Key Words:}

Chronic myocardial ischemia

The canine heart

Ameroid constrictor

Electron microscopy

Sarcoplasmic reticulum

Structural proteins preceding states of myocardial infarction, usually reveal fewer positive findings in clinical practice, such as ST-T changes in electrocardiogram and increased lactate content in coronary venous blood. And the morphologic as well as functional changes of the myocardium itself in the chronic ischemic state have not sufficiently been elucidated yet. This is because of the methodological difficulty to make chronic myocardial ischemia experimentally. In this paper chronic ischemic

(Received on August 11, 1977; Accepted on October 12, 1977)

The 3rd Department of Internal Medicine, Showa University School of Medicine, Tokyo, Japan

* This investigation was supported partly by a grant from the Ministry of Education, Science and Culture in Japan, Research Grant No.057309, 1975.

** Abbreviations were used in this article as follows: S-CK, serum creatine kinase; ATPase, adenosinetriphosphatase. 
myocardium without massive necrosis was produced by placing an Ameroid constrictor around the coronary artery in the dog, and the fine structural and biochemical properties of the heart tissue in chronic ischemia were studied.

\section{MATERIALS AND METHODS}

All the chemicals were the reagent grade. Ameroid constrictors were obtained from Three Point Co. in Canada.

Animal experiments; Twelve adult mongrel dogs, weighing 10 to $15 \mathrm{~kg}$, were anesthetized with intravenous administration of sodium pentobarbital (Nembutal ${ }^{\circledR}$ ) at $30 \mathrm{mg}$ per $\mathrm{kg}$ body weight. Under a regulatory respiration of room air through tracheal intubation, thoracotomy was performed at the left 4 th intercostal space. The circumflex branch of the left coronary artery was isolated out of fatty tissue near of the ramification for about $5 \mathrm{~mm}$ long, and an Ameroid constrictor of the adequate size of the inner diameter with a metal sleeve was placed around the circumflex branch. The chest was closed and the dog was fed until gradual occlusion was produced in the coronary artery by the swelling of Ameroid plastic substance. In 8 of 12 dogs blood samples were obtained in each two to three days to check S-CK activities. At 4 to 5 weeks after operation the dogs were sacrificed under an anesthesia with Nembutal ${ }^{\circledR}$. The beating heart was removed immediately and the posterior part of the left ventricular wall including the posterior papillary muscle was obtained according to the circulating area of the circumflex artery as well as the anterior portion of the left ventricle as a control. For electron microscopic study the central portion of the ischemic left ventricular tissue was divided into 3 parts, i. e., the subendocardial, the middle and the subepicardial portions, and fixed immediately with glutaraldehyde and osmium tetroxide. The remaining tissue was packed in ice for biochemical preparations.

Measurement of serum creatine kinase activity; S-CK was assayed by the method of Okinaka and the co-workers ${ }^{1}$ with addition of cysteine as a stimulator. The transphosphorylated phosphate was assayed by the method of Fiske and SubbaRow?

Electron microscopic study; Ordinary glutaraldehyde-osmium tetroxide double fixing was performed. The myocardial tissue was cut into small blocks with a razor blade in a solution containing $2 \%$ glutaraldehyde, $5 \%$ sucrose and $0.1 \mathrm{M}$ sodium cacodylate (pH 7.4) and kept for 1 hour. Then the blocks were immersed in $1 \%$ osmium tetroxide and $0.1 \mathrm{M}$ sodium cacodylate solution (pH 7.4) for another 1 hour. The fixed sample was embedded in Epon 812 and was sliced with a glass knife on a Porter-Blum ultramicrotome, and observed with a Hitachi-HS-9 electron microscope.

Preparation of sarcoplasmic reticulum; Preparation of sarcoplasmic reticulum was performed principally by the method of Harigaya and Schwartz? Polytron was used for homogenization and $5 \mathrm{mM}$ sodium azide was added in homogenization and preparation to minimize mitochondrial activity. Hitachi 65-P ultracentrifuge and polyethylene tubes were used in precipitation of the microsome fraction. Protein concentration was determined by the biuret procedures.

Preparation of structural proteins; The crude fraction of myocardial tissues containing the total structural proteins were prepared by the method described in the previous paper? The precipitate of the first $9,000 \times \mathrm{X}$ centrifugation in the preparation of sarcoplasmic reticulum was suspended in 9 volumes of $0.1 \mathrm{M} \mathrm{NaCl}$ and 0.01 $\mathrm{M} \mathrm{NaHCO}$ solution and the crude structural proteins were extracted. The last precipitate was divided into two parts and prepared for SDS gel electrophoresis and for ATPase assay as the manner described in the previous paper?

SDS polyacrylamide gel electrophoresis; SDS polyacrylamide gel electrophoresis was performed principally by the method of Weber and Osborn6 5 and $10 \%$ acrylamide gels were used in each sample with 4.1 and $2.7 \%$ of methylene-bisacrylamide with respect to acrylamide, respectevely. Electrophoresis was performed at a constant current of $8 \mathrm{~mA}$ per gel approximately for 3 and 4 hours in 5 and $10 \%$ acrylamide gels, respectively.

Measurement of ATPase activities; ATPase activities of sarcoplasmic reticulum and the total structural proteins were examined by the modified methods of Mead and the co-workers ${ }^{7}$ and Sugita and the associates, 8 respectively. Reactions were performed in the reaction media as follows: 0.02 $\mathrm{M}$ tris-maleate $(\mathrm{pH} 7.2), 0.1 \mathrm{M} \mathrm{KCl}, 0.01 \mathrm{M}$ $\mathrm{MgCl}_{2}, 10^{-5} \mathrm{M} \mathrm{CaCl}_{2}$, and $0.005 \mathrm{M} \mathrm{NaN}_{3}$ for sarcoplasmic reticular ATPase assay, $0.02 \mathrm{M}$ trismaleate (pH 6.8), $0.03 \mathrm{M} \mathrm{KCl}, 2 \times 10^{-5} \mathrm{M} \mathrm{CaCl}_{2}$, $0.001 \mathrm{M} \mathrm{MgCl}_{2}$ and $0.005 \mathrm{M} \mathrm{NaN}_{3}$ for actomyosin-ATPase assay, and $0.02 \mathrm{M}$ tris-maleate $(\mathrm{pH}$ 6.5), $0.6 \mathrm{M} \mathrm{KCl}, 0.01 \mathrm{M} \mathrm{CaCl}_{2}$ and $0.005 \mathrm{M}$ 


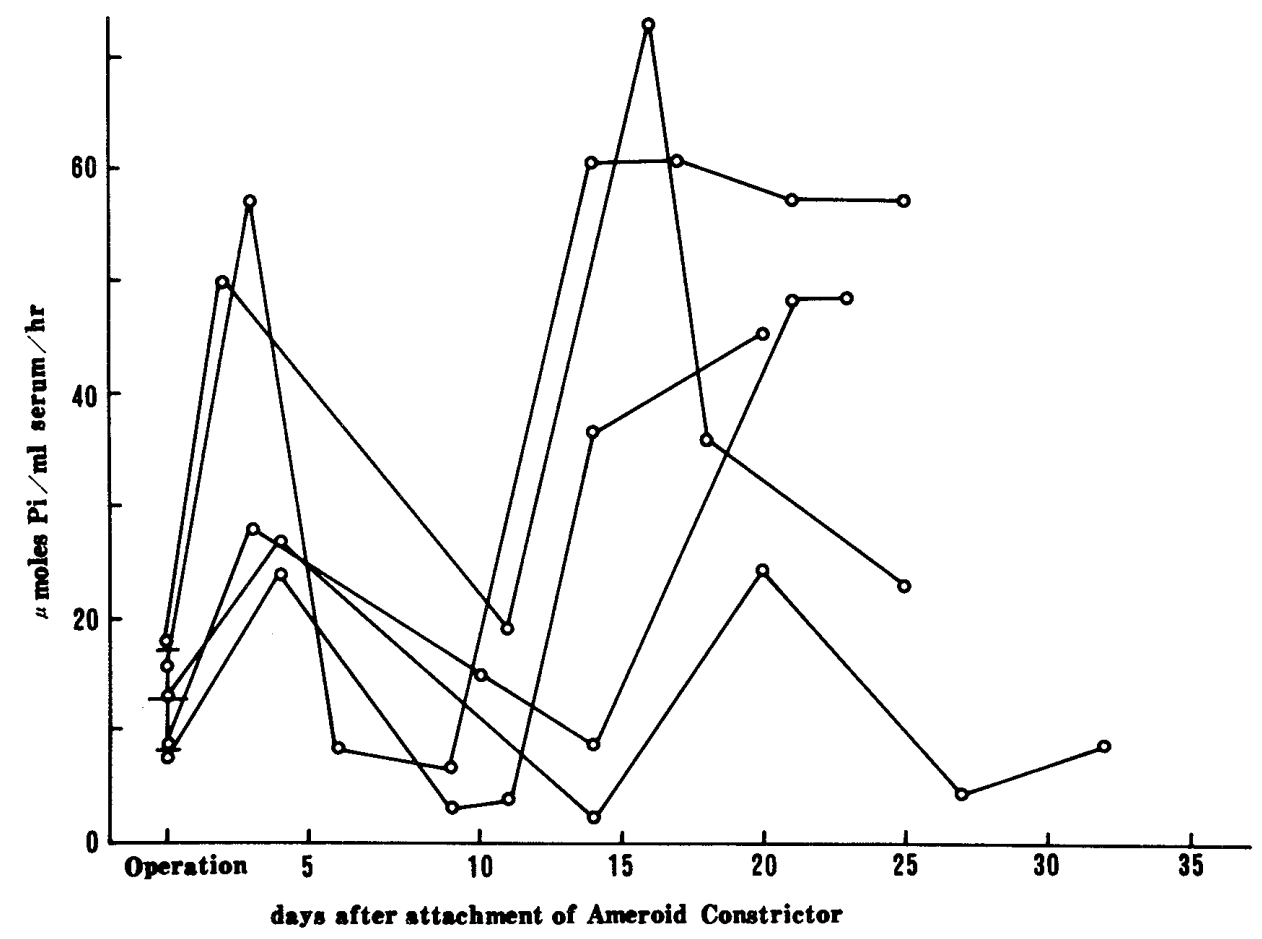

Fig.1. Chronological changes of serum creatine kinase activities. The second elevation of the activities at around three weeks suggests myocardial damage by the Ameroid constrictor.

$\mathrm{NaN}_{3}$ for myosin-ATPase assay, in $0.005 \mathrm{M}$ ATP at $25^{\circ} \mathrm{C}$. 200 micrograms of the sample was applied in a total volume of $1 \mathrm{ml}$. The amounts of phosphate liberated in the reactions were assayed by the method of Fiske and SubbaRow?

Measurement of $\mathrm{Ca}^{+}$binding activities; $\mathrm{Ca}^{+}$ binding and $\mathrm{Ca}^{*}$ uptake were examined by the modified method of Harigaya and Schwartz, as reported by Toba and the co-workers? Millipore filter method was employed and 0.01 microcuries $/ \mathrm{ml}$ of ${ }^{45} \mathrm{Ca}$ was mixed in the reaction media. 200 and 50 micrograms of sarcoplasmic reticulum in a total volume of $1 \mathrm{ml}$ were used for examination of $\mathrm{Ca}^{++}$binding and $\mathrm{Ca}^{++}$uptake, respectively. The reactions were performed in the final concentrations of $\mathrm{Ca}^{++}$of $10 \mu$ moles and $100 \mu$ moles, for 60 seconds and 30 minutes, for $\mathrm{Ca}^{++}$binding and $\mathrm{Ca}^{++}$uptake, respectively. ${ }^{45} \mathrm{Ca}$ taken by sarcoplasmic reticulum was counted in PPO, POPOP and Triton X-100 solution with an Aloka LSC 602 liquid scintillation counter.

\section{RESULTS}

Figure 1 shows S-CK activities after the operation of the Ameroid constrictor attachment. The initial rise of activities, which was observed on the next day to the following day after oper- ation, was assumed to be caused by skeletal muscle injury in the surgery. S-CK activity elevated again at around three weeks after operation. This second rise of activity occurred in 5 of 8 dogs in which S-CK activities were examined, and was assumed to come from the myocardial injury caused by occlusion of the coronary artery by swelling of Ameroid plastic. The pattern of the second increase in S-CK activities was not the same in each dog. As shown in Figure 1, in some case the activities kept their high level constantly, but in another dog the raise was mild and temporary. However, in 3 dogs, the second rise of activities could not be observed. The difference of the changing pattern in S-CK activities was thought to be derived from the different mode and extent of development of collateral circulation.

All of the Ameroid constrictors, placed around the coronary artery, showed more than $50 \%$ of reduction in their lumen diameters, i. e., greater than $75 \%$ of decrease in the cross-sectional areas, at the sacrifice at 24 to 35 days after operation. Those were corresponding to the description of Vineberg and the co-workers. ${ }^{10}$ In one out of 12 dogs, a massive myocardial infarction was observed in the posterior portion of the left 


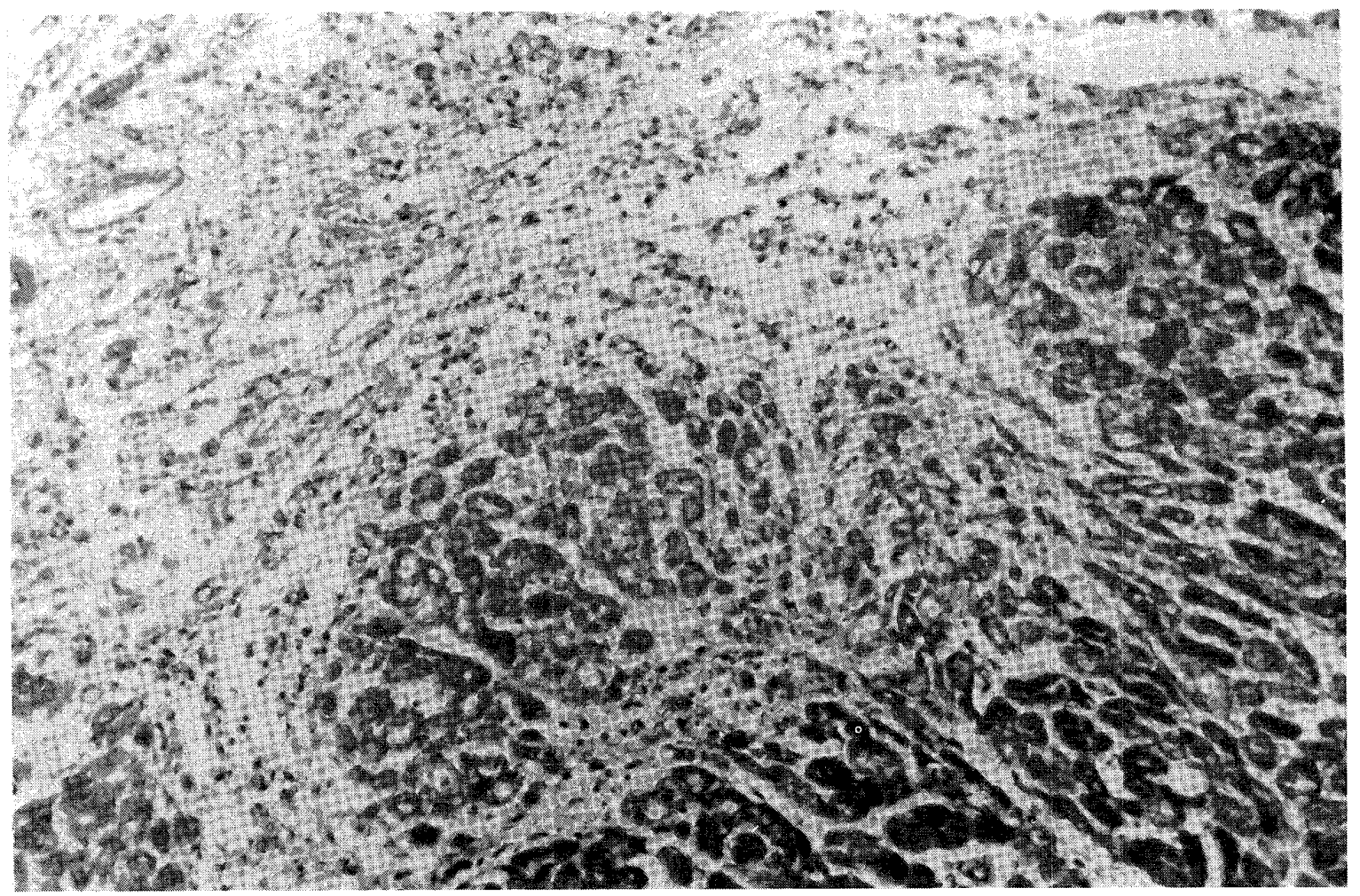

Fig.2. Histological findings of the subendocardial layer of the posterior wall of the left ventricle. Proliferation of connective tissue is found at the left upper portion.

$(\mathrm{H}-\mathrm{E}, \mathrm{x} 100)$

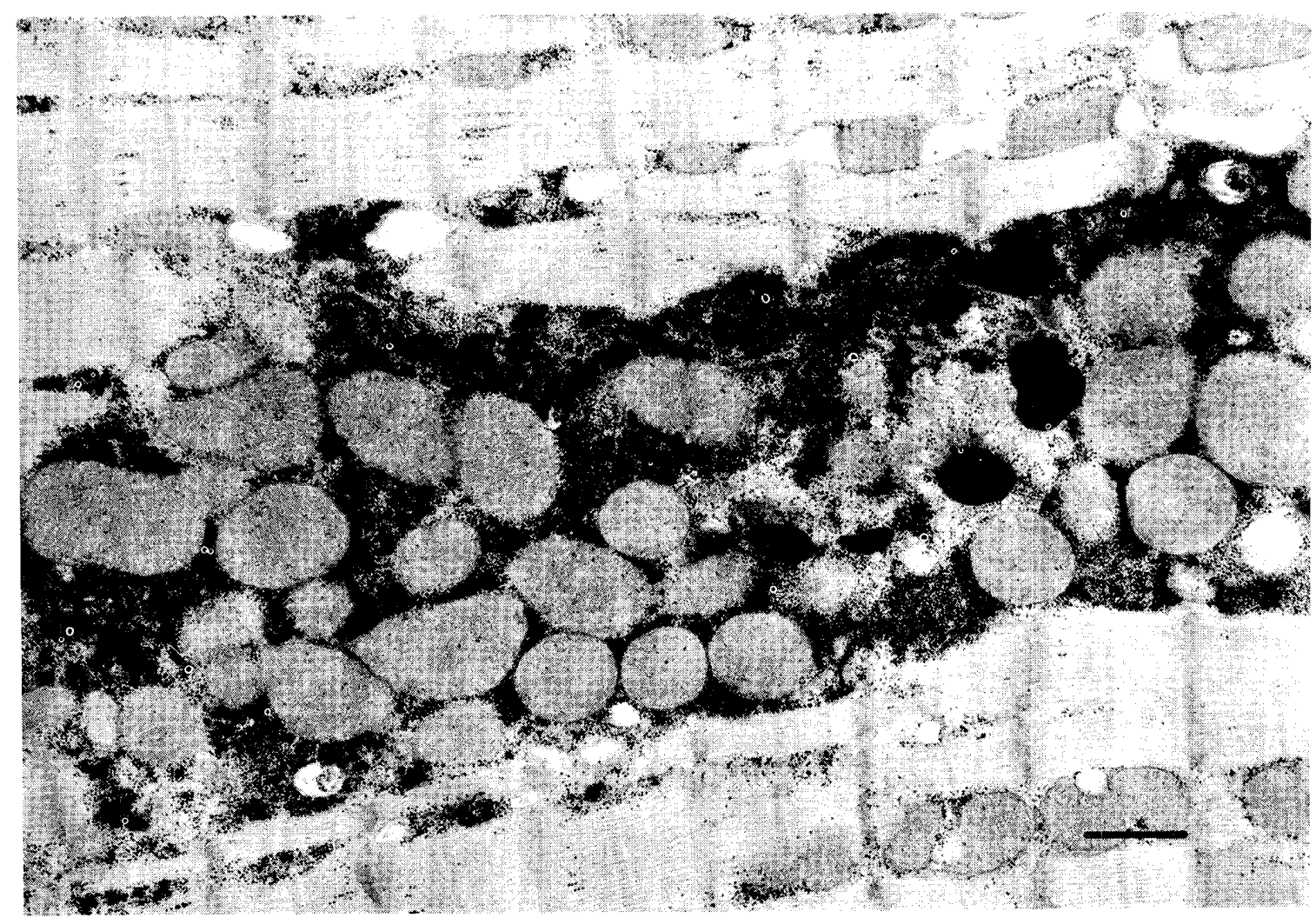

Fig.3. Electron microscopic findings of a cardiac muscle cell in the subendocardial layer. A large conglomeration of glycogen particles is found. A bar indicates 1.0 micron. 


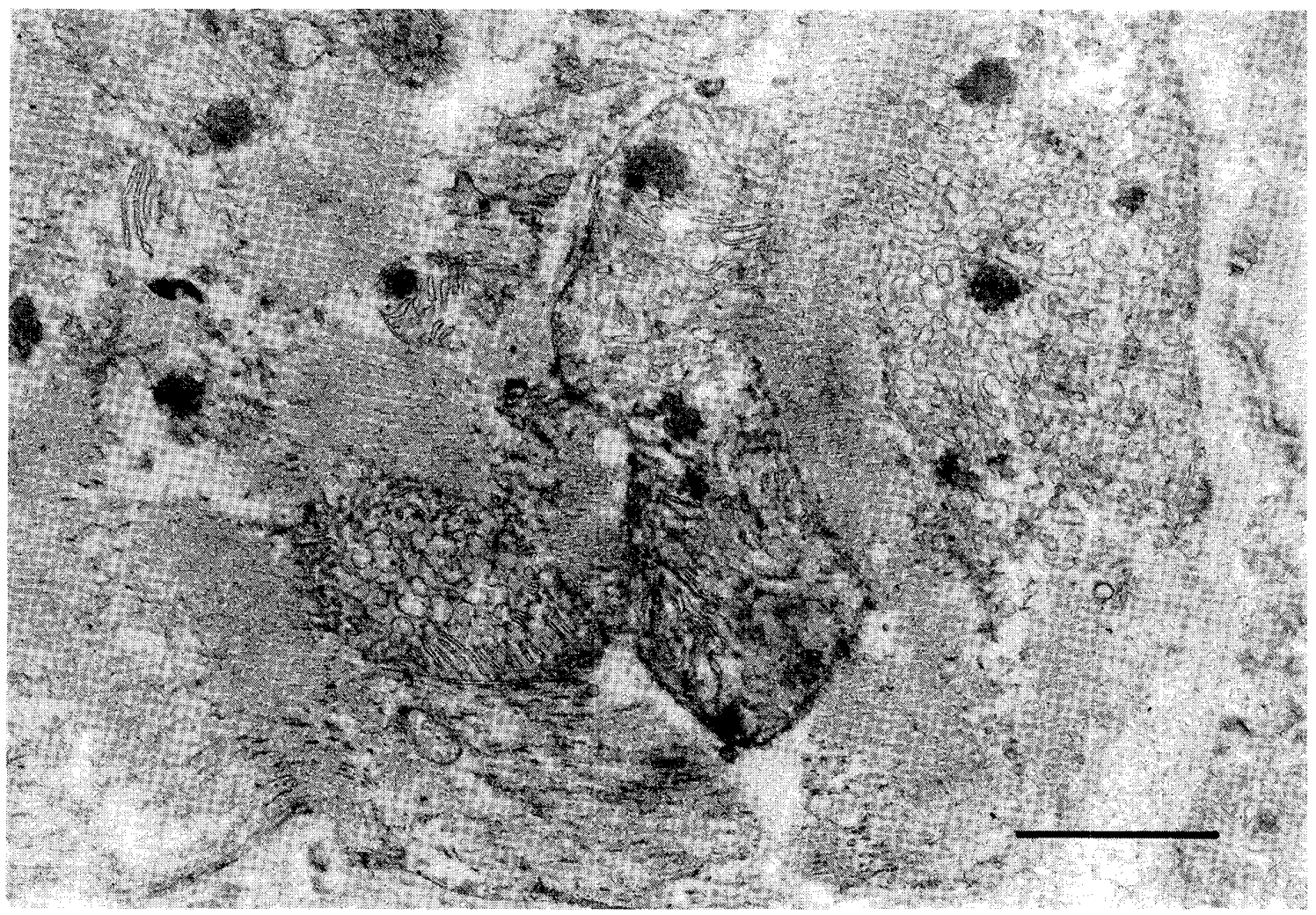

Fig.4. Electron microscopic findings of a cardiac muscle cell in the subendocardial layer. Dense bodies are found in mitochondria. The cristae are vesicular formed. A bar indicates 1.0 micron.

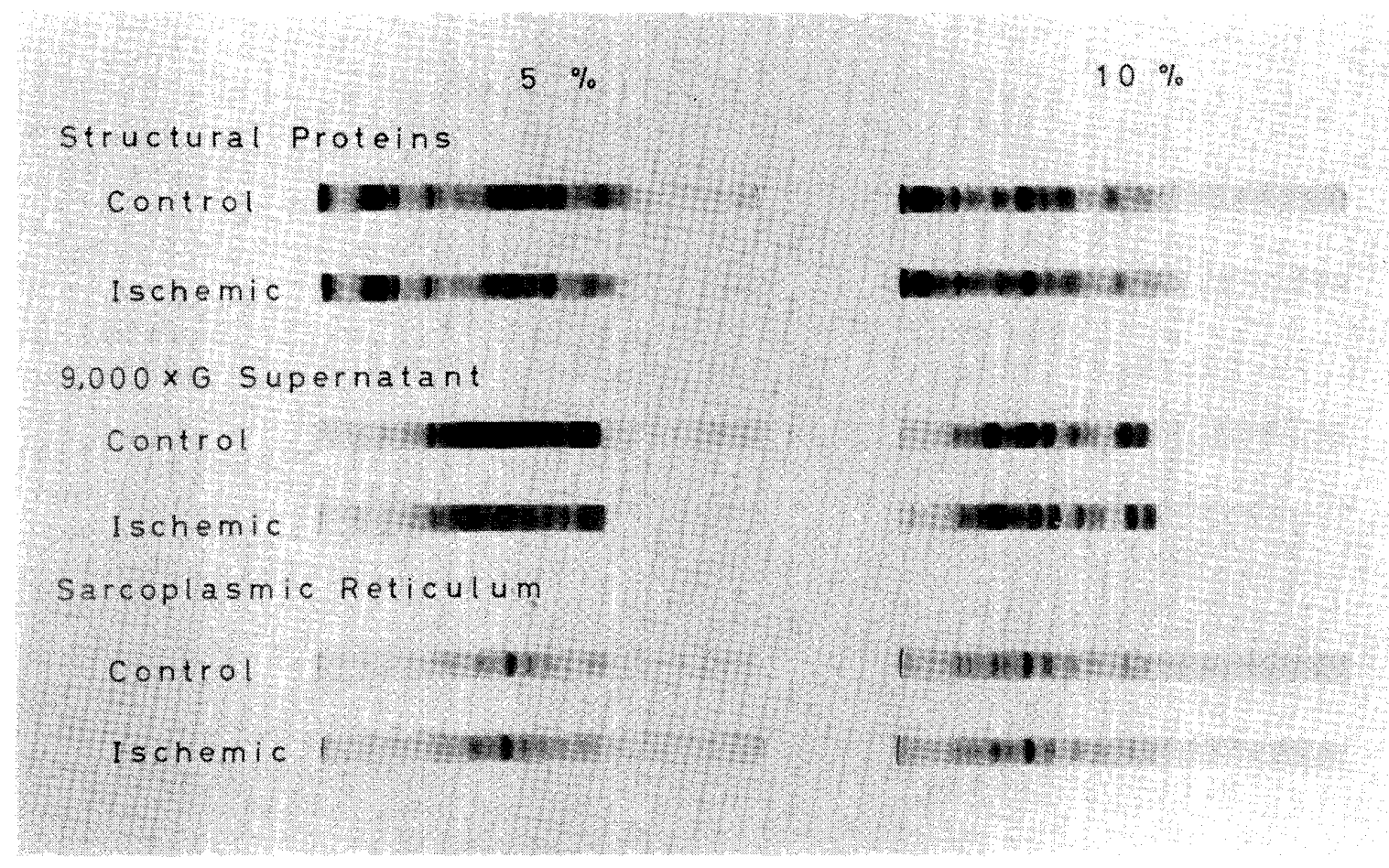

Fig.5. 5 and 10\% SDS acrylamide gels showing the structural proteins, the supernatant of 9,000 $\times G$ centrifugation and isolated sarcoplasmic reticulum. 


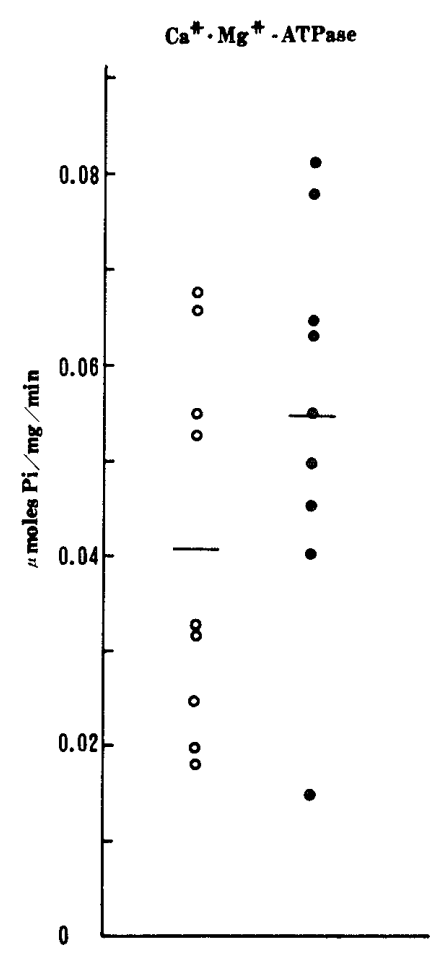

Fig.6. $\mathrm{Ca}^{++}-\mathrm{Mg}^{++}$-ATPase activities of sarcoplasmic reticulum of the myocardial tissue of the left ventricle. $\circ$; non-ischemic portion, $\bullet$; ischemic portion.

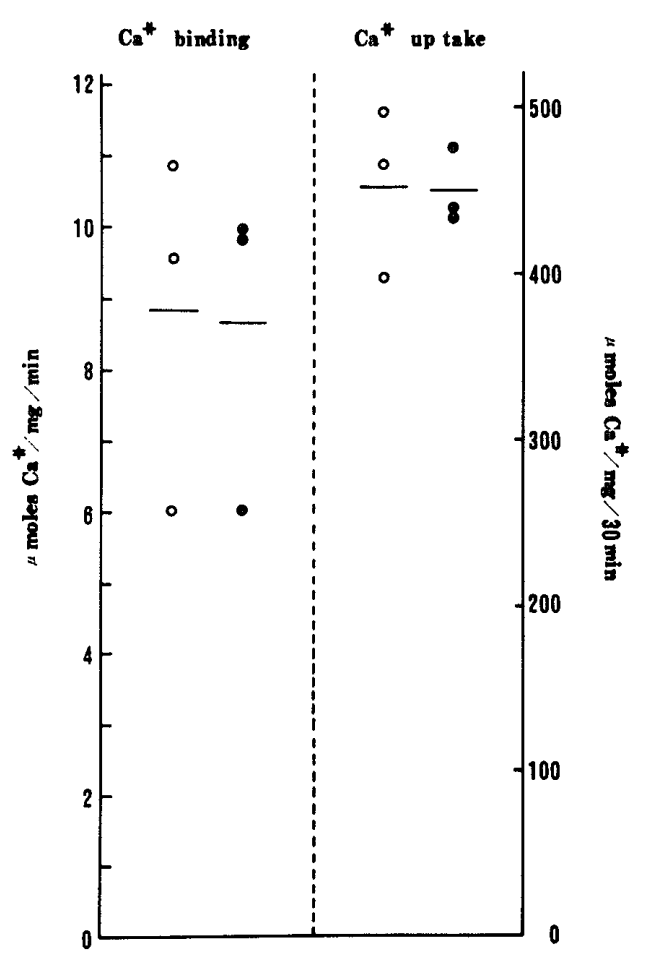

Fig.8. $\mathrm{Ca}^{+}$binding activities of sarcoplasmic reticulum of the myocardial tissue of the left ventricle. $\circ$; non-ischemic portion, $\bullet$; ischemic portion.

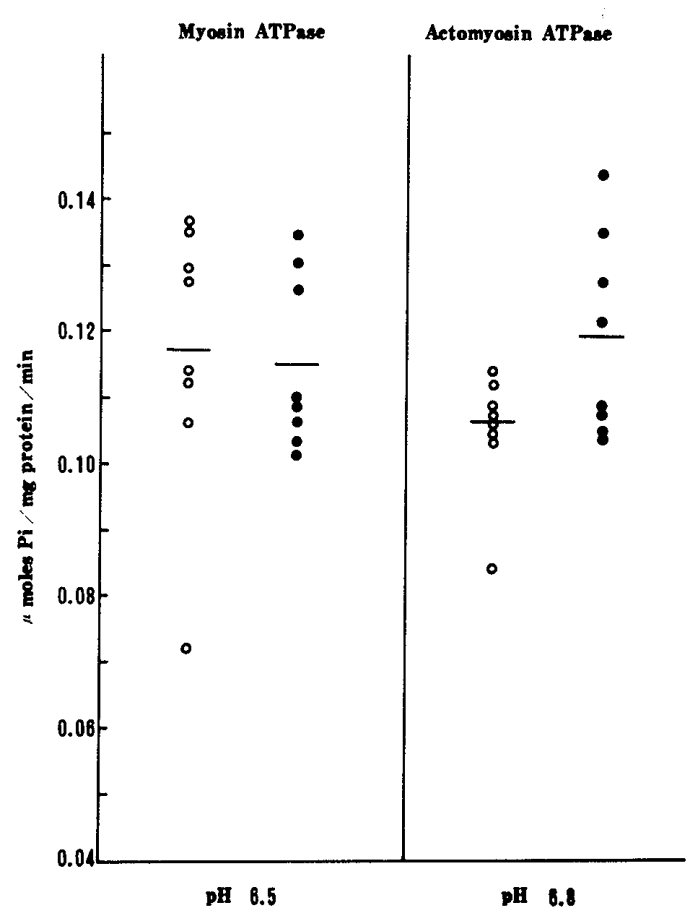

Fig.7. ATPase activities of the structural proteins of the myocardial tissue of the left ventricle. $\circ$; non-ischemic portion, $\bullet$; ischemic portion.

ventricle including the posterior papillary muscle, and data were excluded in this paper. Another 11 hearts were almost normal in their appearances.

In the light microscopic studies, however, proliferation of connective tissue was observed in the subendocardial layer. This subendocardial fibrosis was observed in 7 of the 11 cases. One of these is shown in Figure 2.

Figures 3 and 4 show the electron microscopic findings of the subendocardial muscle cells in the ischemic left ventricle. As shown in Figure 3, a large conglomeration of glycogen particles were observed. However, the fine structures of the microorganellae, the arrangement of myofilaments, mitochondria, etc., were relatively kept intact. This increase in glycogen particles was observed in almost of the experiments. In the cases in which subendocardial fibrosis was observed, the features of cellular necrosis were seen, i.e., dense bodies, swelling and disruption of the cristae and decrease in the density of the substrate, in mitochondria. In these muscle cells, sarcolemma, the arrangement of myofilaments, sarcoplasmic reticulum, however, were not so altered in their appearances. Those changes in the fine structures were much slighter compared 
to those of acute total occlusion of the coronary artery ${ }^{11}$ Also, the fine structural changes were limited to the cells in the subendocardial layer, and cells in the middle and the subepicardial layers were structurally normal.

Figure 5 shows the gel electrophoretic patterns of the myocardial fractions, i.e., structural proteins, the supernatant of centrifugation at 9,000 XG which includes sarcoplasmic reticulum and cytoplasm, and the isolated sarcoplasmic reticulum. In the structural proteins of the nonischemic heart muscle, the patterns, mobilities, i.e., the molecular weights, and the compositions of the protein bands were the same as those in the previous report 5 There found no differences between in the non-ischemic and in the ischemic portion. In the 9,000 XG supernatant and the isolated sarcoplasmic reticulum, the patterns and the mobilities of the bands were almost the same in the non-ischemic and ischemic myocardium.

$\mathrm{Ca}^{++} \cdot \mathrm{Mg}^{++}$-activated ATPase activities of sarcoplasmic reticulum were shown in Figure 6. $\mathrm{Ca}^{++}$ $-\mathrm{Mg}^{++}$-stimulated ATPase activity was 0.041 $\mu$ moles $\mathrm{Pi} / \mathrm{mg} /$ minute in the non-ischemic portion of the myocardium on the average. In the ischemic heart muscle, however, the slightly elevated activity of $0.05 \mu$ moles was obtained. The difference of the activities was statistically significant $(\mathrm{P}<0.05)$. However, basal $\mathrm{Mg}^{++}$ -activated ATPase activities of sarcoplasmic reticulum were equal in the non-ischemic and ischemic heart muscle.

Actomyosin- and myosin-ATPase activities of the structural proteins were shown in Figure 7. Actomyosin-ATPase activity was $0.105 \mu$ moles/ $\mathrm{mg} / \mathrm{minute}$ and $0.120 \mu$ moles in the non-ischemic and ischemic portion, respectively, and the difference of the activities was statistically significant $(\mathrm{P}<0.05)$. Myosin-ATPase activity, however, was $0.117 \mu$ moles $\mathrm{Pi} / \mathrm{mg} /$ minute in the nonischemic portion and $0.115 \mu$ moles in the ischemic portion on the average, respectively, and the difference was statistically insignificant.

Figure 8 shows $\mathrm{Ca}^{++}$binding and $\mathrm{Ca}^{++}$uptake of sarcoplasmic reticulum. In three experiments the same values were obtained in sarcoplasmic reticulum from the non-ischemic and ischemic myocardium.

\section{DISCUSSION}

The morphologic and functional alterations of the chronic ischemic myocardial tissue, which would ordinarily be the preceding appearance of myocardial infarction, have been an interesting subject for a long time. In this experimental study, a method using the Ameroid constrictor, which was designed by Vineberg and the coworkers, ${ }^{10}$ were introduced to make a chronic ischemic heart tissue. Production of chronic myocardial ischemia without massive necrosis in the left ventricle was expected by placing an Ameroid constrictor around the left circumflex coronary artery, with which the myocardial tissue of the circulating area by the corresponding vessel would have become ischemic by the gradual occlusion of the constrictor but would not have become massively necrotic with the development of collateral circulation from the anterior descending branch and the right coronary artery.

The difference in the level of S-CK activities, morphologic and biochemical changes in each individual dog suggests the different development of collateral circulation as well as the different type of coronary artery distribution.

The subendocardial proliferation of connective tissue was so mild that the change could not be detected as subendocardial infarction, however, the fibrosis was observed in most of the experiments in which S-CK activities elevated, and was thought to be the results of ischemic myocardial change. In the subendocardial cells the findings of mild to moderate features of cellular necrosis were found. In the near-subendocardial cells, dense bodies in mitochondria were observed with relative preservation of the finer structures of another organellae. These ultrastuctural findings indicate that the light microscopic changes were of the ischemic type. Jennings and the associates ${ }^{12}$ reported that the subendocardial layer would be most greatly influenced by the diminished coronary flow. The histological as well as electron microscopic changes in the subendocardial layer would correspond to their observations. The increase in glycogen particles in the subendocardial muscle cells was observed in most of the experiments, and this finding was the most characteristic in the chronic ischemic myocardial cells. The cause of this increase is still not established, however, the same phenomena were reported in hypothyroid myocardial cells. ${ }^{3}$ The increase in glycogen particles is conceived as one of the mode of the lowered cellular metabolism.

In comparison with the morphologic alterations, biochemical studies showed relatively poor results. The mild increase in ATPase activities of the structural proteins and sarcoplasmic re- 
ticulum were still undissolved. The author reported the increase in actomyosin-ATPase activities in the initial stage of myocardial infarction. This would be the same phenomenon with the chronic ischemic heart tissue. Kashiwakura and the cowworkers ${ }^{14}$ reported activation of nucleic acid metabolism in the experimental myocardial infarction. Under such circumstances as the initial phase of cellular degeneration activation of some enzymic activities might take place. However, neither any substructural changes were found in the structural proteins as well as sarcoplasmic reticulum, nor $\mathrm{Ca}^{++}$binding and $\mathrm{Ca}^{++}$uptake of the sarcoplasmic reticulum. Lee and the associates ${ }^{15}$ described reduced $\mathrm{Ca}^{++}$ uptake of sarcoplasmic reticulum in 90 minutes of ischemia. Toba and the co-workers ${ }^{9}$ recognized one of the major protein bands of microsome fraction decreased at 3 hours in the similar experiment. The absence of these substructural and functional changes in the chronic ischemic myocardium would indicate that the intensity of ischemia was much slighter than in acute occlusion of the coronary artery, and that the ischemic damage was limited to the subendocardial restricted portion.

However, as shown in the electron microscopic observations, the essentials of the changes in chronic ischemic myocardial cells are the same as those in the early phase of myocardial infarction.

\section{Acknowledgements}

The authors would sincerely thank Dr. Fumihide Yoshida and Dr. Akinori Sato of Showa University for their collaborations. The authors are also greatly indebted to Prof. Yasumitsu Nakai of Showa University for his sincere guidance about electron microscopy.

\section{REFERENCES}

1. OKINAKA, S., SUGITA, H., MOMOI, H., TOYOKURA, Y., WATANABE, T., EBASHI, F., \& EBASHI, S.: Cysteine-stimulated serum creatine kinase in health and disease. J. Lab. Clin. Med. 64: 299, 1964.

2. FISKE, C. H. \& SUBBAROW, Y.: The colorimetric determination of phosphorus. J. Biol. Chem. 66: 375: 1925.
3. HARIGAYA, S. \& SCHWARTZ, A.: Rate of calcium binding and uptake in normal animal and failing human cardiac muscle. Circ. Res. 25: 781, 1969.

4. GORNALL, A. G., BARDAWILL, C. J., \& DAVID, M. M.: Determination of serum protein by means of biuret reaction. J. Biol. Chem. 177: 751, 1949.

5. KATAGIRI, T.: Changes of cardiac structural proteins in myocardial infarction. Jap. Heart $J$. 18: 711, 1977.

6. WEBER, K. \& OSBORN, M.: The reliability of molecular weight determination by dodecylsulfatepolyacrylamide gel electrophoresis. J. Biol. Chem. 244: 4406, 1969.

7. MEAD, R. J., PETERSON, M. B., WELTY, J. D.: Sarcolemmal and sarcoplasmic reticular ATPase activities in the failing canine heart. Circ. Res. 29: $14,1971$.

8. SUGITA, H., OKIMOTO, K., EBASHI, S., \& OKINAKA, S.: Biochemical alterations in progressive muscular dystrophy with special emphasis to the sarcoplasmic reticulum. Expiratory concepts in muscular dystrophy and related disorders. Excerpta Medica Int. Congr. Ser. No 147: 321, 1966.

9. TOBA, K., KATAGIRI, T., \& TAKEYAMA, Y.: Studies on the cardiac sarcoplasmic reticulum in myocardial infarction. Jap. Circul. $J$. in press.

10. VINEBERG, A., MAHANTI, B., \& LITVAK, J.: Experimental gradual coronary artery occlusion by Ameroid constrictors. Surgery 47: 765, 1960.

11. OZAWA, K., KATAGIRI, T., YOSHIDA, F., NIITANI, H., \& NAKAI, Y.: Electron microscopic studies on ATPase activities in myocardial infarction. Recent Advances in Studies on Cardiac Structure and Metabolism. Vol.12. Cardiac Adaptation. ed. KOBAYASHI, T., ITO, Y., \& RONA, G. p.471, 1978. University Park Press, Baltimore.

12. JENNINGS, R. B., GANOTE, C. E., \& REIMER, K. A.: Ischemic tissue injury. Amer. J. Pathol. 81: 179,1975

13. SUZUKI, T., TOMINAGA, K., ISHIZAWA, Y., TAZIMA, T., KANDA, H., BABA, N., SHINKAI, T., YAMANE, O., KANAZAWA, N., KAWAI, Y., \& MURATA, K.: Electron microscope observations on the biopsied cardiac muscle cells from the patients with hypothyroidism. J. Clin. Electron Microscopy 9: 517, 1976.

14. KASHIWAKURA, Y., ABE, M., ARAI, C., TANAKA, H, YABE, Y., HASEGAWA, M., TSUZUKI, S., YOSHIMURA, M., \& KAMEDA, H.: J. Jap. Coll. Angiol. 15: 618, 1975. (in Japanese)

15. LEE, K. S., LADINSKY, H., \& STUCKEY, J. H.: Decreased $\mathrm{Ca}^{+}$uptake by sarcoplasmic reticulum after coronary artery occlusion for 60 and 90 minutes. Circ. Res. 21: 439, 1967. 